\title{
Inflammatory and Oxidative Stress Responses of an Alveolar Epithelial Cell Line to Airborne Zinc Oxide Nanoparticles at the Air-Liquid Interface: A Comparison with Conventional, Submerged Cell-Culture Conditions
}

\author{
Anke-Gabriele Lenz, ${ }^{1}$ Erwin Karg, ${ }^{2}$ Ellen Brendel, ${ }^{1}$ Helga Hinze-Heyn, ${ }^{1}$ Konrad L. Maier, \\ Oliver Eickelberg, ${ }^{1}$ Tobias Stoeger, ${ }^{1}$ and Otmar Schmid ${ }^{1}$ \\ ${ }^{1}$ Comprehensive Pneumology Center, Institute of Lung Biology and Disease, Helmholtz Zentrum München, \\ Ingolstaedter Landstrasse 1, 85758 Neuherberg, Germany \\ ${ }^{2}$ Joint Mass Spectrometry Center, Helmholtz Zentrum München, Ingolstaedter LandstraBe 1, 85758 Neuherberg, Germany
}

Correspondence should be addressed to Anke-Gabriele Lenz; alenz@helmholtz-muenchen.de

Received 27 August 2012; Accepted 23 November 2012

Academic Editor: Irma Rosas

Copyright (C) 2013 Anke-Gabriele Lenz et al. This is an open access article distributed under the Creative Commons Attribution License, which permits unrestricted use, distribution, and reproduction in any medium, provided the original work is properly cited.

\begin{abstract}
The biological effects of inhalable nanoparticles have been widely studied in vitro with pulmonary cells cultured under submerged and air-liquid interface (ALI) conditions. Submerged exposures are experimentally simpler, but ALI exposures are physiologically more realistic and hence potentially biologically more meaningful. In this study, we investigated the cellular response of human alveolar epithelial-like cells (A549) to airborne agglomerates of zinc oxide ( $\mathrm{ZnO}$ ) nanoparticles at the ALI, compared it to the response under submerged culture conditions, and provided a quantitative comparison with the literature data on different types of particles and cells. For $\mathrm{ZnO}$ nanoparticle doses of 0.7 and $2.5 \mu \mathrm{g} \mathrm{ZnO} / \mathrm{cm}^{2}$ (or 0.09 and $0.33 \mathrm{~cm}^{2} \mathrm{ZnO} / \mathrm{cm}^{2}$ ), cell viability was not mitigated and no significant effects on the transcript levels of oxidative stress markers (HMOX1, SOD-2 and GCS) were observed. However, the transcript levels of proinflammatory markers (IL-8, IL-6, and GM-CSF) were induced to higher levels under ALI conditions. This is consistent with the literature data and it suggests that in vitro toxicity screening of nanoparticles with ALI cell culture systems may produce less false negative results than screening with submerged cell cultures. However, the database is currently too scarce to draw a definite conclusion on this issue.
\end{abstract}

\section{Introduction}

Exposure to airborne particles has been linked to adverse health effects including pulmonary inflammation, thrombosis, neurodegeneration, and cardiovascular disease [13]. A number of studies have indicated that particles with diameters below $100 \mathrm{~nm}$ have a more pronounced effect than larger particles, implying that nanoparticles (or ultrafine particles) are more toxic on a mass basis [3-6].

Zinc is an ubiquitous transition metal associated with industrial emissions (e.g., mining and smelting of zinc) that typically appears in the form of zinc oxide $(\mathrm{ZnO})$ in ambient particulate matter (PM) [7-9]. $\mathrm{ZnO}$ is known as an occupational hazard, since inhalation of high concentrations of $\mathrm{ZnO}$ formed during welding activities can lead to metal fume fever $[10,11]$ associated with a marked upregulation of proinflammatory markers in the lung [11-13]. In addition to these inadvertently generated $\mathrm{ZnO}$ nanoparticles, there is a variety of $\mathrm{ZnO}$ nanostructures, which have shown great potential for nanotechnological products including manufacturing and pharmaceutical applications $[14,15]$. However, there is increasing concern that the desirable technological 
characteristics of nanosized $\mathrm{ZnO}$ may be countervailed by increased health and environmental risks due to toxic effects that do not occur for bulk $\mathrm{ZnO}$. While the enhanced toxicity potential of nanoparticles is at least in part due to their inherently large surface-to-mass ratio $[4,6,16,17]$, there is also evidence that some metal particles trigger additional toxicological pathways making them more toxic (per surface area) than many other particle types (e.g., carbon, polystyrene) [18].

Cell-based in vitro toxicity assays are widely used to assess the toxicity of nanoparticles. These toxicological in vitro studies are typically performed using cell cultures grown under submerged conditions, where the toxin/stressor is dissolved or suspended (nonsoluble nanoparticles) directly in the cell culture medium covering the cells. While this approach is experimentally simple, submerged cell exposures have two main limitations. First, the particle dose interacting with the cells is typically unknown since the particle fraction reaching the cells can neither be readily measured nor always be calculated from the hydrodynamic properties of the particles (size, density, shape) [19]. This problem is especially pronounced for particles smaller than about $100 \mathrm{~nm}$, when diffusion becomes the dominant transport mechanism [20], leading to loss of particles to lateral walls. The second limitation is that submerged cell-culture conditions represent an unrealistic and artificial environment for alveolar epithelial cells in the lungs. In vivo exposure through inhalation involves deposition of PM onto the lung epithelium, that is, the cells are exposed to inhaled air (airborne PM) from one side while being in contact with the blood circulation from the other side. Since submerged cell systems are completely covered with cell culture medium (see Figure 1(b)), in vivo exposure conditions can be mimicked more realistically by exposing epithelial cells at the air-liquid interface (ALI) (Figure 1(a)). Various ALI exposure systems have been introduced [2128], but it is unclear whether the enhanced experimental complexity of the ALI exposures compared to submerged exposures is justified. For that reason, we compared the cellular response to nanoparticles after ALI and submerged exposure.

One of the most widely accepted paradigms of particle toxicity states that particles induce inflammation via oxidative stress and subsequent activation of redox-sensitive transcription factors [29]. Nel and colleagues refined and expanded this concept into the hierarchical oxidative stress paradigm $[30,31]$ suggesting the transition from an antioxidant defense response (tier1) to inflammation (tier2) and finally to cytotoxicity (tier3), if the induced stress is strong enough. Proinflammatory responses mediated by oxidative stress have been proposed to be not only crucial but also the most sensitive readout for particle toxicity [30]. We therefore measured three proinflammatory cytokines (interleukin-8 (IL-8), IL-6, and granulocyte macrophage colony-stimulating factor (GM-CSF) and three oxidative stress markers (heme oxygenase 1 (HMOX1), superoxide dismutase (SOD-2), and glutamate-cysteine synthetase, catalytic subunit (GCS)) by qRT-PCR.
In this study the first ALI exposure of human epitheliallike cells (A549) to airborne agglomerates of $\mathrm{ZnO}$ nanoparticles is presented. The dose- and time-dependent cellular responses of the cells were compared after $\mathrm{ZnO}$ exposure under submerged and ALI conditions at two dose levels $\left(0.7\right.$ and $\left.2.5 \mu \mathrm{g} / \mathrm{cm}^{2}\right)$ and two time points $(0 \mathrm{~h}$ or $2 \mathrm{~h}$ after incubation). From the exposure-specific in vitro toxicity data, we deduced corresponding lowest observed effect levels (LOELs) and compared them with similar studies available in the literature.

\section{Materials and Methods}

2.1. Materials. Common laboratory chemicals were purchased from Sigma-Aldrich (Taufkirchen, Germany). The particle exposure experiments were performed with commercially available powder of $\mathrm{ZnO}$ nanoparticles (NPs) (Alfa Aesar, Ward Hill, MA, USA ID 43141) with primary particle diameters between 24 and $71 \mathrm{~nm}$ (manufacturer information) and a measured BET surface area of $13 \pm 2 \mathrm{~m}^{2} / \mathrm{g}$, which agrees with the manufacturer specifications $\left(15-45 \mathrm{~m}^{2} / \mathrm{g}\right)$ within experimental uncertainties.

2.2. Cell Culture. In this study, the alveolar epithelial-like cell line (A549) from a human lung adenocarcinoma (obtained from ATTC, Manassas, VA, USA) representing the alveolar type II phenotype [32] was used.

For ALI exposure (Figure 1(a)), A549 cells were seeded on perforated Anodisc membranes (Whatman, Maidstone, UK; aluminum oxide, diameter: $47 \mathrm{~mm}$, pore size: $0.2 \mu \mathrm{m}$ ) with about $1.6 \times 10^{5} / \mathrm{cm}^{2}$ cells and cultivated in $25 \mathrm{~mL}$ Petri dishes under submerged conditions for $9 \mathrm{~d}$ at $37^{\circ} \mathrm{C}$ in DMEM/F12/L-Glut/15 mM HEPES buffer (Invitrogen, Germany) containing $100 \mathrm{U} / \mathrm{mL}$ penicillin, $100 \mu \mathrm{g} / \mathrm{mL}$ streptomycin, and 10\% FCS. After $9 \mathrm{~d}$ a confluent layer with a cell density of approximately $5.1 \times 10^{5} / \mathrm{cm}^{2}$ was obtained. 1 hour prior to particle exposure, the cells were transferred to the ALI, by taking the six cell-covered membranes from the Petri dishes and placing them in two cell exposure chambers (described below) using the same culture medium as above but without FCS. This arrangement allows nourishment of the cells with a cell culture medium through the perforated membrane from the bottom and exposure to airborne particles from the top. Immediately after ALI exposure, the cells were washed with PBS and gently scrapped off the membranes after adding trypsin/EDTA (for RTPCR). For reasons discussed below, one of the cell-covered membranes in each ALI exposure chamber was incubated for a postincubation period of $2 \mathrm{~h}$ (submerged in $3 \mathrm{~mL}$ medium at $37^{\circ} \mathrm{C}$ ) prior to determination of the biological endpoints.

For exposure under submerged conditions (Figure 1(b)), A549 cells were seeded at $2.5 \times 10^{5} / \mathrm{cm}^{2}$ in 24 -well plates and incubated for $16 \mathrm{~h}$ in DMEM/F12/L-Glut/15 mM HEPES buffer (Invitrogen, Germany) containing $100 \mathrm{U} / \mathrm{mL}$ penicillin, $100 \mu \mathrm{g} / \mathrm{mL}$ streptomycin, and $10 \%$ fetal calf serum (FCS) resulting in a cell density of approximately $3.5 \times$ $10^{5} / \mathrm{cm}^{2}$. 
2.3. Exposure at the ALI. The $\mathrm{ZnO}$ powder was aerosolized with a commercially available venturi-type dry powder disperser (Model SAG 410, TOPAS, Leipzig, Germany) optimized for output stability by taking the following measures: (i) the metal venturi nozzle was replaced by a ceramic nozzle to avoid chemical and mechanical erosion, (ii) the particle reservoir and the inlet of the venturi nozzle were permanently flushed with dry nitrogen instead of filtered ambient air to minimize clogging due to moisture effects, (iii) the scraper in the reservoir was modified to allow for permanent stirring of the powder especially at the bottom of the reservoir, (iv) the aerosol output was passed through a buffer volume to remove extremely large particles (sedimentation) and smoothen fluctuation in $\mathrm{ZnO} \mathrm{NP}$ concentration, and (v) particle growth due to coagulation was minimized by diluting the aerosol $(1: 1)$ with compressed filtered air directly after generation.

A detailed description of the ALI exposure chamber used here was provided by Bitterle et al. [21]. Briefly, $\mathrm{ZnO}$ aerosol was generated at a flow rate of $1.5 \mathrm{~L} / \mathrm{min}$ with the generator described above and evenly distributed to two cell exposure chambers (one for particle exposure or control) holding three cell-covered Anodisc membranes each. The two chambers were operated in parallel using symmetric flow splitters with the control atmosphere (clean air) being obtained by filtration with a PALL filter (BB50TE, PALL, Newquay, UK). Each chamber was supplied with $0.25 \mathrm{~L} / \mathrm{min}$ aerosol-laden air (or filtered air for control), which was directed at a radially symmetric stagnation point flow profile over the cell-covered membrane. This design assures spatially uniform particle deposition onto the cells at a deposition fraction, which was experimentally determined to be almost constant ( $2 \%$ of the particles in the sample flow) over a broad particle size range of about 50 to $500 \mathrm{~nm}$ [33], due to the compensating effects of diffusional and gravitational deposition [34]. The air flow was conditioned to $37^{\circ} \mathrm{C}$ and $99.5 \%$ relative humidity. A more detailed description of the ALI exposure chamber is provided by Bitterle et al. [21].

The particle number size distribution was measured immediately downstream of the exposure units with a scanning mobility particle sizer (SMPS, model 3080, TSI, St. Paul, MN, USA, combined with a TSI model 3025A condensation particle counter). By maintaining a constant particle concentration (within about $\pm 20 \%$ ) during the $3 \mathrm{~h}$ exposure time, the cell-delivered particle dose increased linearly with time. After $3 \mathrm{~h}$ the final dose was reached and the biological parameters were evaluated at this time point (referred to as $0 \mathrm{~h}$ ) and after an additional 2 -hour postincubation time at $37^{\circ} \mathrm{C}$ under submerged conditions (referred to as $2 \mathrm{~h}$ ).

\subsection{Exposures under Submerged Conditions. For $\mathrm{ZnO}$ expo-} sures under submerged conditions, the culture medium in each well was replaced with serum-free medium into which NPs of 0.7 and $2.5 \mu \mathrm{g} / \mathrm{cm}^{2}$ of well area were given by adding the appropriate volume of a freshly prepared $1 \mathrm{mg}$ $\mathrm{ZnO} / \mathrm{mL} \mathrm{H}_{2} \mathrm{O}$ stock suspension (vortexed and sonicated twice for $1 \mathrm{~min}$ intermittently immediately prior to application). The size distribution of the $\mathrm{ZnO}$ NPs in suspension was determined with a dynamic light scattering sizer (DLSS) (HPPS 5001 Malvern Instruments Ltd., Worcestershire, UK). As shown in the Results section, gravitational settling was sufficient for all particles to reach the cells within $1 \mathrm{~h}$. Thus, the final particle dose was delivered to the cells after a $1 \mathrm{~h}$ exposure time. The biological parameters are reported relative to control conditions (incubated cell cultures without $\mathrm{ZnO}$ ) either directly after the exposure time (referred to as $0 \mathrm{~h}$ ) or after an additional $2 \mathrm{~h}$ postincubation time (referred to as $2 \mathrm{~h}$ ).

2.5. qRT-PCR Measurements of Proinflammatory and Oxidative Stress Markers (mRNA Expression). Gene expression levels of interleukin-8 (IL-8), IL-6, granulocyte macrophage colony-stimulating factor (GM-CSF), the antioxidant enzyme heme oxygenase 1 (HMOX1), superoxide dismutase (SOD2 ), and glutamate-cysteine synthetase, catalytic subunit (GCS), were measured by RT-PCR with SYBR green. After exposure, cells were lysed and homogenized in a buffer containing guanidine isothiocyanate and total RNA was isolated using a RNeasy kit according to the method recommended by the manufacturer (Quiagen, Germany). To detect cytokine mRNA expression, RNA was reverse-transcribed into cDNA using the First-Strand cDNA Kit (Pharmacia, Germany). For PCR amplification, the above-mentioned cDNA served as template and $3 \mu \mathrm{L}$ was added together with the specific 5 ' and 3 ' primers to the Absolute QPCR SYBR Green Mixes from ABgene (Thermo Fisher Scientific, Germany). Quantitative PCR was performed in a TaqMan instrument (TaqMan ABI Prism 7700 Sequence Detector System; PerkinElmer, Germany) offering the advantage of fast and realtime measurement of fluorescent signals during amplification. The housekeeping gene glyceraldehyde-3-phosphate dehydrogenase (GAPDH) was used as internal reference to normalize the RNA levels of the genes being studied. The following primers were used (sense; antisense): IL-8 (ATGACTTCCAAGCTGGCCGTGGCT; TCTCAGCCCTCTTCAAAAACTTCTC), IL-6 (GACAGCCACTCACCTCTTC; CCAGGCAAGTCTCCTCAT), GM-CSF (CTTCCTGTGCAACCCAGATT; CTTGGTCCCTCCAAGATGAC), HMOX1 (AAGATTGCCCAGAAAGCCCTGGAC; AACTGTCGCCACCAGAAAGCTGAG), SOD-2 (CCTGGAACCTCACATCAACG; AACCTGAGCCTTGGACACC), GCS (GTTCTTGAAACTCTGCAAGAGAAG; ATGGAGATGGTGTATTCTTGTCC), GAPDH (CCATGAGAAGTATGACAACAGCC; TGGCAGGTTTTTCTAGACGG).

2.6. Viability Assay. Cell viability was measured with the cell proliferation reagent WST-1 (Roche Applied Sciences, Germany). The WST-1 reagent is a ready-to-use solution which was added to the cells at a concentration of $100 \mu \mathrm{L} / \mathrm{mL}$. Light absorbance was measured after $30 \mathrm{~min}$ incubation at $37^{\circ} \mathrm{C}$ at $450 \mathrm{~nm}$ (iEMS Reader MF, Lab Systems).

2.7. Statistical Analysis. Results are presented as geometric mean and geometric standard error of the mean of at least four separate experiments $(n=4-7)$, since the data are not normally but close to log normally distributed. Data 


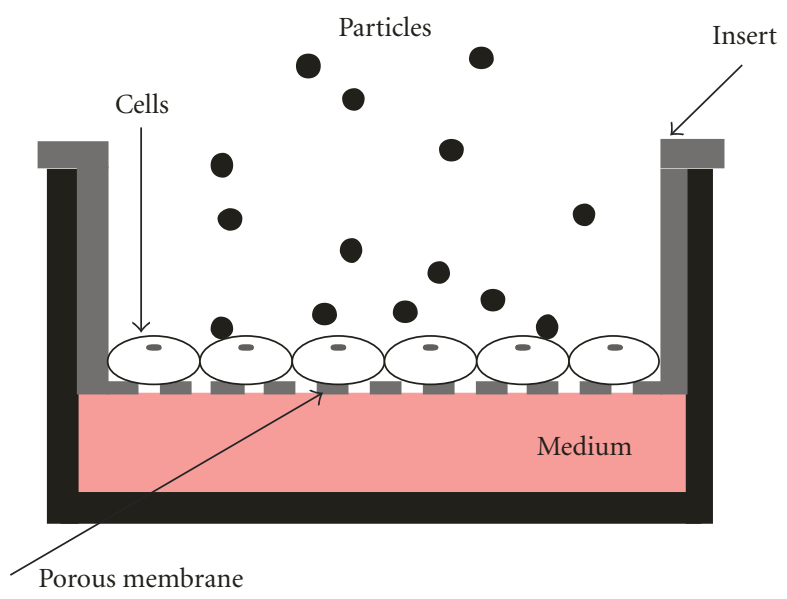

(a) ALI condition

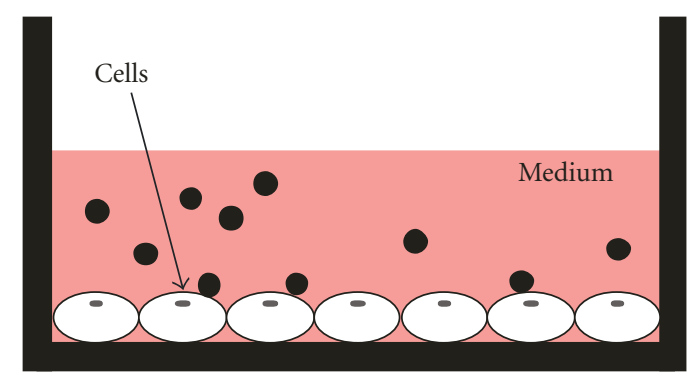

(b) Submerged condition

FIGURE 1: Schematic of the two cell exposure models used for studying particle-cell interaction. (a) Exposure at the air-liquid interface (ALI): airborne particles are directly deposited on cells grown at the air-liquid interface. (b) Exposure under submerged conditions: particles were suspended directly in the cell culture medium covering the cells.

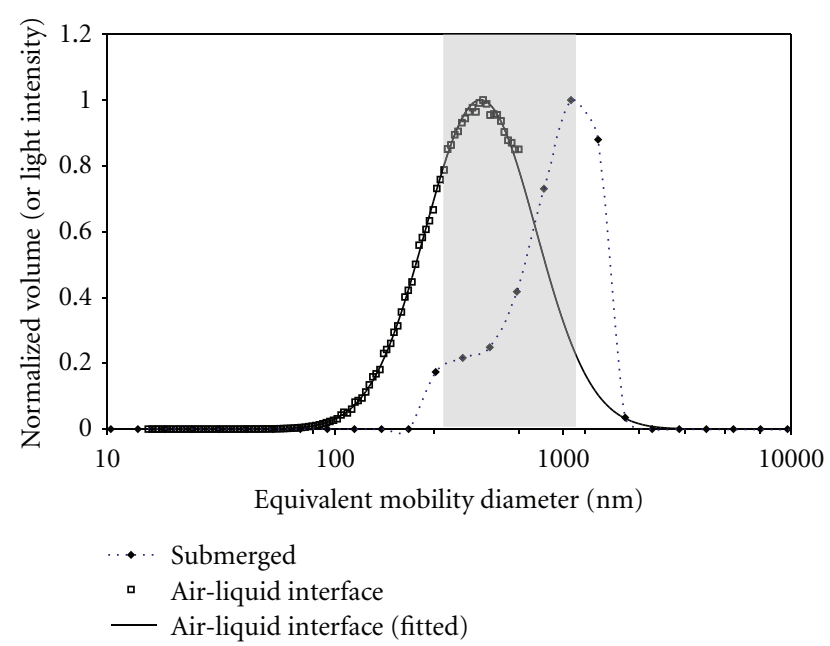

Figure 2: Typical $\mathrm{ZnO}$ particle size distribution during ALI submerged (SUB) exposure conditions, respectively. When comparing the particle size distributions during ALI and submerged exposures, one has to consider that different sizing instruments were used. As discussed in the text, both SMPS (ALI) and DLSS (submerged) measure the particle mobility diameter. Furthermore, the volume distribution (normalized to the maximum volume level) is approximately equal to the (normalized) light intensity distribution in the size range between about 315 to $1250 \mathrm{~nm}$ (highlighted by the grey shaded area), which encompasses most of the size regime of interest here. The ALI size distributions showed volume-weighted median diameters of about $335 \pm 40 \mathrm{~nm}$ and a width of $1.77 \pm 0.05$ (geometric standard deviations). For the submerged conditions (SUB), dynamic light scattering measurements (DLSS) showed $\mathrm{ZnO}$ aggregates of about $900 \mathrm{~nm}$ (mobility diameter) with a less pronounced ( 20\%) secondary mode near $350 \mathrm{~nm}$. Thus it is evident that the average $\mathrm{ZnO}$ agglomerates were considerably larger during submerged than during ALI exposure condition. For comparison with other studies, the number-weighted size distribution of the $\mathrm{ZnO}$ particles during ALI exposure had a count median diameter of about $140 \mathrm{~nm}$ (data not shown). comparisons were carried out using the Kruskal Wallis test (Statgraphics plus 5.0), a nonparametric one-way analysis of variance (ANOVA). $P<0.05$ was considered as statistically significant.

\section{Results}

3.1. Particle Size Distribution. The measurement of particle size distributions in different media, such as air and liquid during ALI and submerged exposure, respectively, requires the use of different measurement techniques, here scanning mobility sizing with an SMPS (ALI) and dynamic light scattering using a DLSS (submerged). The SMPS counts individual particles, which are size-selected based on their migration speed in an electric field [35]. The DLSS determines the mobility diameter from the time-dependent fluctuations of the scattered light intensity signal from an ensemble of suspended particles [36]. While both instruments measure the mobility diameter ( $x$-axis of size distribution as depicted in Figure 2), the SMPS counts individual particles and the DLSS reports a signal proportional to the light intensity of a given particle [35]. Since the light intensity signal cannot be directly related to particle number concentration, the SMPS number distribution was converted into effective volume (or mass) distribution, which can be related to the scattered light intensity as described below. Accurate performance and comparability of both instruments was validated with NISTtraceable (National Institute of Standards and Technology, USA) reference particles.

For ALI exposures, the SMPS measurements of the $\mathrm{ZnO}$ aerosol revealed a count median (mobility) diameter (CMD) and geometric standard deviation of $141 \pm 12 \mathrm{~nm}$ and $1.77 \pm$ 0.05 , respectively. Since the CMD is larger than the diameter of the primary $\mathrm{ZnO}$ NPs $(24-71 \mathrm{~nm})$, it is evident that the $\mathrm{ZnO}$ aerosol mainly consists of agglomerated (nonspherical) structures. For the two dose levels studied here, the mean 
and standard deviation of the number concentration was $(3.5 \pm 0.45) \times 10^{5}$ and $(9.5 \pm 0.9) \times 10^{5}$ particles $/ \mathrm{cm}^{3}$. This corresponds to average mass concentrations of $10.1 \mathrm{mg} / \mathrm{m}^{3}$ and $30.4 \mathrm{mg} / \mathrm{m}^{3}$, respectively, with an almost constant mass (or volume) median diameter ( \pm standard deviation) of $335 \pm$ $40 \mathrm{~nm}$. As mentioned above, for comparison of SMPS and DLSS, data the SMPS data were converted from numberinto mass-based (volume-based) size distribution taking into account the nonspherical shape of the $\mathrm{ZnO}$ particles as follows. First, the number size distribution was converted into volume distribution (assuming spherical particle shape for now) and fitted as lognormal distribution using the Hatch-Choate equations for consistent conversion of the count median into mass median diameter. Integration of the volume distribution yields the total volume. For correct conversion into particle mass accounting for the nonspherical particle shape, the volume is multiplied by the effective density of $4.6 \mathrm{~g} / \mathrm{cm}^{3}$ [37], which was experimentally determined by dividing the gravimetrically determined particle mass by the (spherical) particle volume determined from the SMPS data (see Figure 2). The fact that the effective density of the $\mathrm{ZnO}$ aerosol is smaller than the bulk density of $\mathrm{ZnO}\left(5.6 \mathrm{~g} / \mathrm{cm}^{3}\right)$ is consistent with the agglomerated structure of the $\mathrm{ZnO}$ particles [37]. The relatively small difference between effective and bulk density indicates that the particles have a relatively compact (sphere-like) structure.

Although exposures under submerged conditions were performed with the same $\mathrm{ZnO}$ particles as used for ALI exposures, $\mathrm{ZnO}$ particles suspended in the cell culture medium were more agglomerated and hence larger than those dispersed in air (ALI exposure). As seen from the DLSS size distribution depicted in Figure 2, the $\mathrm{ZnO}$ particles, suspended in cell medium for $30 \mathrm{~min}$, displayed a minor mode near $350 \mathrm{~nm}$ (about $20 \%$ of total mass) and a more pronounced mode near $900 \mathrm{~nm}$ ( $~ 80 \%$ of total particle mass). For accurate comparison of the DLSS sizing data, one has to relate the volume-based size distribution derived from the SMPS data with the light intensity values of the DLSS. For particle sizes near the wavelength $\lambda$ of the light source (between about $\lambda / 2$ and $2 \lambda$ ), it has been shown that the light-intensity-to-volume ratio is almost constant [38]. Thus for the Malvern DLSS $(\lambda=633 \mathrm{~nm})$, we can assume that the normalized light intensity distribution (normalized to the maximum of the intensity spectrum) as shown in Figure 2 is approximately equal to the normalized volume (or mass) distribution obtained from the SMPS in the size range between 315 and $1250 \mathrm{~nm}$ (shaded area in Figure 2), which covers most of the size range of interest for the present study. Outside this range, the light intensity level is systematically lower than the corresponding volume level [38].

In summary, it is evident that the ALI size distribution was dominated by $\mathrm{ZnO}$ agglomerates with a volume median diameter near $350 \mathrm{~nm}$. While this mode is also seen during submerged exposures, most of the particle mass $(\sim 80 \%)$ resides in a mode near $900 \mathrm{~nm}$ indicating that suspending the $\mathrm{ZnO}$ particles in cell culture medium for 30 min leads to enhanced particle size due to agglomeration effects.
3.2. Particle Dosimetry. For reliable comparison of the cellular dose-response relationship under ALI and submerged culture conditions, the biological response should be correlated to the cell-delivered particle dose $\left(D_{M}\right)$ normalized to the cell-covered surface area. Here $D_{M}$ is given by

$$
D_{M}=\frac{M \text { Dep }}{A_{\text {cell }}},
$$

where $M$ is the particle mass passing or floating over the cell layer during the exposure, Dep is the deposition efficiency (fraction of particles depositing onto the cell layer), and $A_{\text {cell }}$ is the area covered by the exposed cells.

For the ALI exposure, $M$ is calculated from $M=m Q t$, where $m$ is the average mass concentration ( $\mathrm{ZnO}$ mass per volume air; 10.1 and $30.4 \mathrm{mg} / \mathrm{m}^{3}$ for the low and high dose level, resp.), $Q=0.25 \mathrm{~L} / \mathrm{min}$ is the volumetric flow rate passing over the cell layer, and $t=3 \mathrm{~h}$ is the exposure time. With $A_{\text {cell }}=12.6 \mathrm{~cm}^{2}$ (per culture membrane) and Dep $=0.02[21,33]$, we find from (1) that $D_{M, A L I}=0.7$ and $2.2 \mu \mathrm{g} \mathrm{ZnO} / \mathrm{cm}^{2}$ for the low and high doses, respectively. With the specific BET surface area of $13 \mathrm{~m}^{2} / \mathrm{g}$, this corresponds to BET surface area doses of 0.09 and $0.29 \mathrm{~cm}^{2} \mathrm{ZnO} / \mathrm{cm}^{2}$, respectively.

For submerged exposures, we substitute $M$ by $M=m V$ in (1), where $m$ is the $\mathrm{ZnO}$ particle mass concentration in the stock suspension (here $1 \mathrm{mg} / \mathrm{mL}$ ) and $V$ is the volume of the $\mathrm{ZnO}$ stock suspension (here 1.4 or $5 \mu \mathrm{L}$ ) added to the culture medium $(1 \mathrm{~mL})$. Under the assumption that all particles contained in the medium will deposit on the cells within $3 \mathrm{~h}$ (i.e., Dep $=1$; will be justified below) we find from (1) that $D_{M \text {,sub }}=0.7$ and $2.5 \mu \mathrm{g} \mathrm{ZnO} / \mathrm{cm}^{2}$ (with $A_{\text {cell }}=$ $2.0 \mathrm{~cm}^{2}$ ) or 0.09 and $0.33 \mathrm{~cm}^{2} \mathrm{ZnO} / \mathrm{cm}^{2}$, respectively.

As a justification for Dep $=1$ under submerged conditions, the following aspects were considered [39]: (I) Is the particle deposition dominated by sedimentation or diffusion (the latter would result in loss of particles to the lateral walls and hence Dep $<1$ ) and (II) if sedimentation dominates particle deposition, is the exposure time long enough for all particles (even the ones near the top of the cell culture well) to reach the cells at the bottom of the well? To address these issues, we calculated the gravitational settling velocity and the mean diffusional displacement speed of the particles in water to be $56 \mathrm{~mm} / \mathrm{h}$ and $0.033 \mathrm{~mm} / \mathrm{h}$, respectively [20], where we assumed an average particle diameter of $900 \mathrm{~nm}$ (see Figure 2). Since the ratio of gravitational to diffusional displacement speed is about 1700 for $900 \mathrm{~nm}$ particles with a density of $4.6 \mathrm{~g} / \mathrm{cm}^{3}(\mathrm{ZnO})$, sedimentation is the dominant deposition mechanism; that is, negligible particle loss to lateral walls is expected. Secondly, for a sedimentation speed of $56 \mathrm{~mm} / \mathrm{h}$ and a $50 \mathrm{~mm}$ depth of the cell culture medium ( $1 \mathrm{~mL}$ of medium; $2 \mathrm{~cm}^{2}$ cross-sectional area of well), all $\mathrm{ZnO}$ particles are expected to deposit onto the cells within about $1 \mathrm{~h}$.

As a caveat we note that due to differences in deposition kinetics during ALI and submerged exposures (as described above), the final dose was delivered to the cells after $3 \mathrm{~h}$ and $1 \mathrm{~h}$, respectively. 
3.3. Biological Endpoints. Several biological endpoints were investigated after $\mathrm{ZnO}$ exposures of the A549 cells representing human alveolar epithelium type II cells [32, 40]. First, cell viability was determined to exclude the possibility that the observed effects of $\mathrm{ZnO}$ NPs on gene expression levels are negatively biased due to cytotoxic effects. No effects on cell viability were seen for the $\mathrm{ZnO}$ concentrations investigated here for both ALI (viability in \% of (submerged) unchallenged control: $93.5 \% \pm 2.1$, at $\leq 2.2 \mu \mathrm{g} / \mathrm{cm}^{2}$ ) and submerged conditions $\left(94 \% \pm 7.99\right.$, at $\left.\leq 2.5 \mu \mathrm{g} / \mathrm{cm}^{2}\right)$. Hence, the cellular response to $\mathrm{ZnO}$ exposure was not significantly hampered by reduced cell viability and there was no significant reduction in cell viability due to exposure of the cells to the air-liquid interface.

ALI exposure of A549 cells to ZnO NPs caused elevated levels of mRNA coding for IL-8, GM-CSF, and IL-6 as shown in Figure 3(a) (left panel). IL-8 showed a significant increase with increasing dose and time. The time response of GM-CSF was similar to that of IL-8, but no significant dose effect was observed. IL-6 was increased for all ALI exposure scenarios, but no significant dependence on dose or time was observed. On the other hand, the oxidative stress markers HMOX1 and SOD-2 showed no significant increases in mRNA expression except for GCS mRNA which was slightly, but statistically significantly increased for both time points of the high dose level (1.8-fold and 3-fold increased at $0 \mathrm{~h}$ and $2 \mathrm{~h}$, resp., see Figure 3(b), left panel).

Under submerged conditions, the expression levels of all proinflammatory markers were lower than those under ALI conditions (Figure 3(a), right panel). For IL-8 only the high dose showed a significant induction of 1.9-fold and 3.7-fold at the two time points, and IL- 6 was increased (4-fold) for the high dose at $2 \mathrm{~h}$. Out of the three oxidative stress markers, a significant expression was observed only for HMOX1 (2.7fold) after $2 \mathrm{~h}$ (Figure 3(b), right panel).

In summary, compared to the submerged conditions, ALI exposure showed slight, but statistically significant enhancements in mRNA expression of IL-8, GM-CSF, and IL-6 for all dose levels and time points as well as for the high dose level of GCS (both time points). The only case where the submerged exceeded the ALI response was HMOX1 (high dose, $2 \mathrm{~h}$ ). Thus the ALI exposure system was generally more sensitive to mRNA induction than the submerged exposure assay especially for the proinflammatory markers.

\section{Discussion}

To the best of our knowledge, the data presented here represents the first in vitro measurements of the cellular response to an exposure of airborne agglomerates of $\mathrm{ZnO}$ particles at the ALI. We model inhalation exposure to $\mathrm{ZnO}$ NPs with the widely used A549 cell line. A549 cells represent human alveolar epithelial type II cells [32, 40], which are considered the defenders of the alveoli because they are important producers of cytokines [41] and metabolically more active than type I pneumocytes [42, 43]. Consequently, A549 cells are widely regarded as a valid model cell system for pulmonary particle toxicity studies $[44,45]$.
The data presented here are consistent with positive dose-response correlations. Focusing on ALI conditions first, we find that the IL- 8 response $(2 \mathrm{~h}$ postincubation time) is enhanced for the higher concentration with a $94.5 \%$ confidence level ( $P=0.055)$. A positive dose-response is also found for GCS ( $2 \mathrm{~h}$ postincubation time; $95 \%$ confidence level). On the other hand, no significant response is found for HMOX1 and SOD2 for any of the concentrations used here, since none of these parameters is upregulated. Furthermore, the lack of a dose-response correlation for GM-CSF and IL-6 might be due to reaching the saturation levels already for the lower concentration. Similar considerations can be conducted for the submerged cell culture data. A positive dose-response is seen for IL-8 (both time points), IL-6, and HMOX-1 after $2 \mathrm{~h}$ postincubation time. All other parameters are not changed.

While historically in vitro particle toxicity studies have been performed with submerged cell systems, various ALI exposure systems have recently been introduced in an attempt to mimic more realistically the exposure conditions during particle inhalation [21-28]. Further advantages of ALI exposures include the preservation of the physicochemical characteristics of the airborne particles (e.g., particle agglomeration and/or particle-medium interactions such as partial dissolution of $\mathrm{ZnO}$ in cell culture medium are avoided [46]), the synergistic effects between particulate and gaseous compounds can be investigated (e.g., relevant for combustion emissions) and the biological complexity can be more adequately represented (e.g., surfactant coating can be added to of alveolar epithelial cells). Last but not least, it is typically technically simpler to determine the cell-delivered particle dose under ALI than submerged conditions [47, 48]. Some of the recently introduced ALI exposure systems utilize aerosolized nanoparticle suspensions instead of dry airborne nanoparticles [28]. While these systems allow for cell exposure at the ALI, partial dissolution and possibly agglomeration of the nanoparticles cannot be ruled out with these systems.

Although ALI exposures have become more widely used, there is very little quantitative information on whether and how the exposure type (ALI and submerged) affects the cellular response. A summary of the currently available studies is listed in Table 1 and will be discussed below. In Table 1 all but one investigator utilizes gene expression analysis instead of protein determination as toxicological readout. Gene expression is commonly preceding protein expression; however, the latter can additionally be regulated at the posttranscriptional level. In some cases, protein expression without associated gene expression can occur. However, this is not the case for any of the markers listed in Table 1. Hence, both protein and gene expressions are suitable for toxicity studies. The advantages of gene expression analysis by qPCR include higher sensitivity than the measurement of protein levels, simultaneous quantification of several markers and higher cost efficiency. For these reasons, gene expression analysis was used in the present study to screen for representative markers of different acute response pathways related to inflammation and oxidative stress. 
As mentioned above, the cellular response to nanoparticles depends on numerous aspects including cell type, preand postprocessing of the cells, state of cell differentiation, particle dose, deposition kinetics, and physicochemical particle characteristics. Matching all of these aspects is very difficult, if not impossible, since, for instance, the state of cell differentiation is inherently different under submerged and ALI culture conditions [49-51] and particle deposition rates onto the cell system may vary significantly for submerged and ALI conditions, since they depend on agglomeration state and carrier medium of the particles (air or liquid). Hence, any study on cellular response under ALI versus submerged cell conditions should provide as much details on these aspects as possible as is done in the following section.

Exposures were performed at two dose levels with no statistically significant difference for the two exposure types (low: $0.7 \mu \mathrm{g} / \mathrm{cm}^{2}$; high: $2.2 \mu \mathrm{g} / \mathrm{cm}^{2}$ (ALI) and $2.5 \mu \mathrm{g} / \mathrm{cm}^{2}$ (submerged)). In addition, the cell type (A549) was identical for both exposure types and the cell densities (cells per $\mathrm{cm}^{2}$ ) were similar at the time of exposure. Preprocessing of the cells was different because it had to be adapted to the two different exposure conditions, whereas postprocessing of the cells was identical. There have been several studies indicating differences in cell differentiation due to transfer of the cells from submerged to ALI culture conditions even at the first investigated time points between a few hours and $1 \mathrm{~d}$ [49-51]. However, we assume that in the present study the state of cell differentiation was similar, since cells were kept under submerged conditions except for a brief period of time during ALI exposure ( $1 \mathrm{~h}$ prior to exposure; $3 \mathrm{~h}$ during exposure). This is supported by the fact that we found no statistically significant differences in cell viability as well as IL- 8 mRNA and HMOX-1 mRNA after transfer of the cells to ALI conditions. This is an important aspect, since with an already strained antioxidant defense, as, for instance, reported by [49], cells may be more susceptible to the effects of the particle exposure. Other important aspects for ALI-submerged comparisons are related to the particle characteristics. For ALI conditions, the count median and mass median particle diameters were $141 \mathrm{~nm}$ and $335 \mathrm{~nm}$, respectively, and the rate of particle deposition onto the cells was constant (within 20\%) during the $3 \mathrm{~h}$ exposure time by keeping the sample flow and the $\mathrm{ZnO}$ aerosol concentration constant. Under submerged conditions, the size of the $\mathrm{ZnO}$ particles increased from a mass median diameter of about $350 \mathrm{~nm}$ to about $900 \mathrm{~nm}$ within about $30 \mathrm{~min}$ due to agglomeration, which results in an approximately 3 -fold deposition rate; that is, the entire $\mathrm{ZnO}$ dose is delivered to the cells with about $1 \mathrm{~h}$. Hence, differences in deposition kinetics may affect the comparison of the two exposure scenarios. Since the total number of primary particles in the medium is not changing with the agglomeration state, agglomeration does not affect the number of primary particles or the surface area dose delivered to the cells. However, agglomerate size may influence the biological response of the A549. Furthermore, $\mathrm{ZnO}$ is partially soluble in aqueous media [30]. Hence, the $\mathrm{Zn}^{2+} / \mathrm{ZnO}$ ratio may be different under ALI and submerged conditions with higher $\mathrm{Zn}^{2+} / \mathrm{ZnO}$ ratios to be expected under submerged conditions due to the relatively high dissolution of $\mathrm{ZnO}$ in the cell culture medium.

In spite of some experimental differences between submerged and ALI exposures, as described above, it is instructive to compare the $\mathrm{ZnO}$ dose-response curves observed under ALI and submerged conditions and relate these findings to similar data sets for other particle and pulmonary cell types from the literature. This can be done by determining the dose range in which the lowest observed effect levels (LOELs) occurred. If none of the two dose levels investigated here showed a statistically significant response, the LOEL lies above the highest dose level $\left(>2.5 \mu \mathrm{g} / \mathrm{cm}^{2}\right)$. If the low dose showed no response, but the high dose did, then the LOEL falls in the range of $0.7-2.5 \mu \mathrm{g} / \mathrm{cm}^{2}$. If both dose levels showed a response, then the LOEL is below $<0.7 \mu \mathrm{g} / \mathrm{cm}^{2}$.

As seen from Table 1, our data indicate that four biological parameters (mRNA levels of IL-8, GM-CSF, IL-6, and GCS) showed lower LOELs and hence elevated response levels under ALI conditions. The results for two of the six investigated parameters (HMOX1, SOD-2) were inconclusive, since the investigated dose regime was not broad enough to discern differences in LOEL. Similar results were reported by other studies with pulmonary cell lines and primary cells reported in the literature (Table 1). Volckens and colleagues [26] exposed primary human bronchial epithelial cells to concentrated coarse ambient particulate matter. Applying our LOEL scheme to their data indicates that the mRNA levels of IL- 8 and HMOX1 were more pronounced under ALI conditions, while no conclusive result was found for COX-2 mRNA expression. Holder and colleagues [24] investigated Diesel exhaust particles with a human bronchial epithelial cell line (16HGE14o). As seen from Table 1, they found no conclusive result for IL- 8 protein levels but state that a much smaller dose was required to induce similar IL- 8 expression levels. We contend that this claim is not substantiated by their data, since in contrast to submerged exposures their IL-8 response under ALI conditions was not statistically significantly different from unity (according to their own statistical analysis). It is important to note that the currently available data on submerged versus air-liquid exposure comparisons is limited, but diverse. As seen from Table 1 the data were generated with both immortalized and primary cell cultures as well as with different particle types, various biological endpoints, and different pre-/postprocessing protocols. These differences are likely to result in exposuredependent differences in the state of cell differentiation, particle-cell interaction, and deposition kinetics. In spite of this heterogeneity, none of the currently available studies has identified a biological parameter, which responded to be more sensitive to particle challenge under submerged exposure conditions than under ALI conditions. While it cannot be inferred that this is true for all possible biological endpoints, the currently available data suggest that air-liquid interface exposures are a more "conservative" toxicity test than submerged systems, that is, ALI cell systems are likely to lead to less false negatives.

To put the particle dose levels typically used for in vitro toxicity testing into perspective, it is instructive to consider 


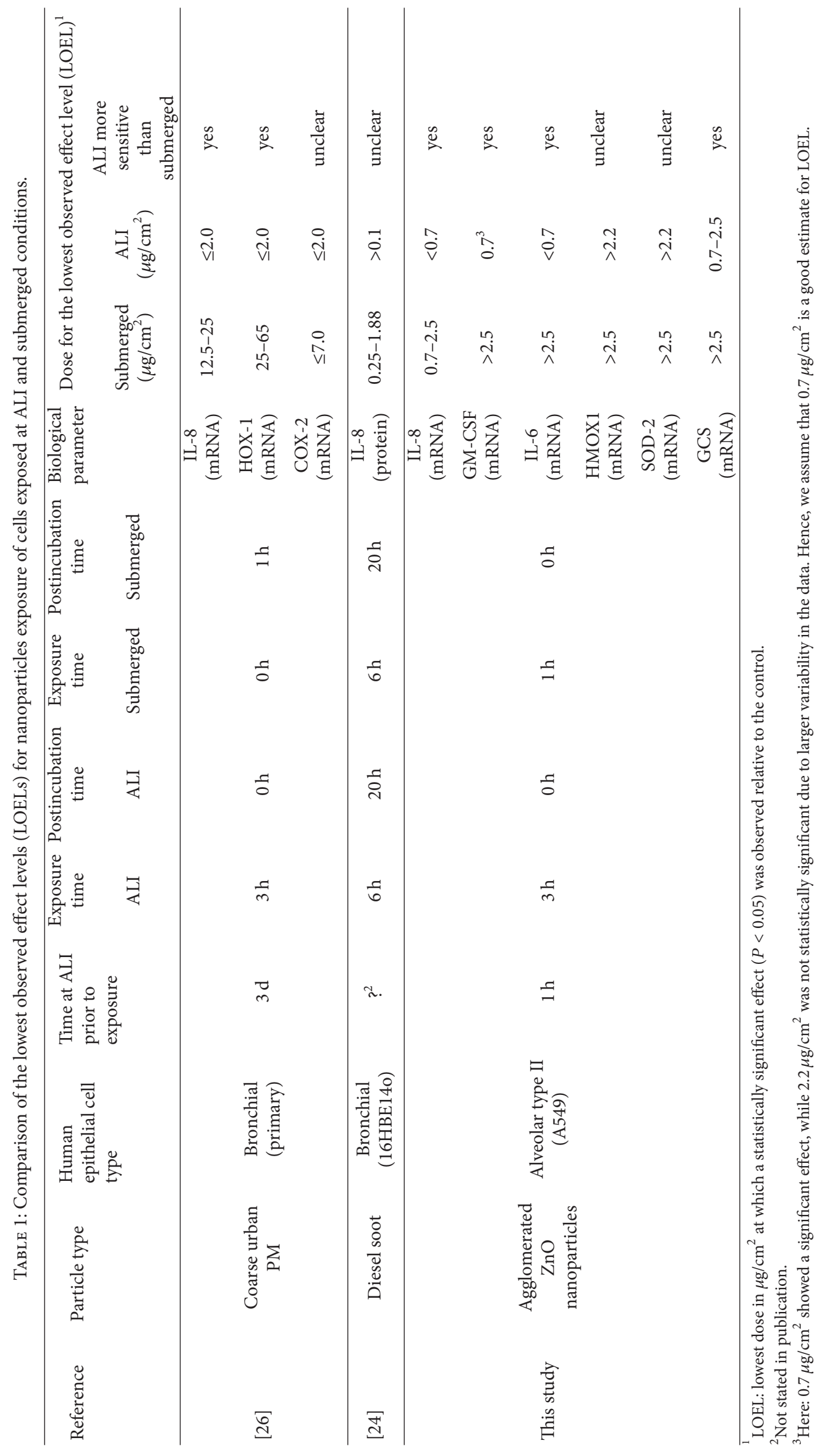




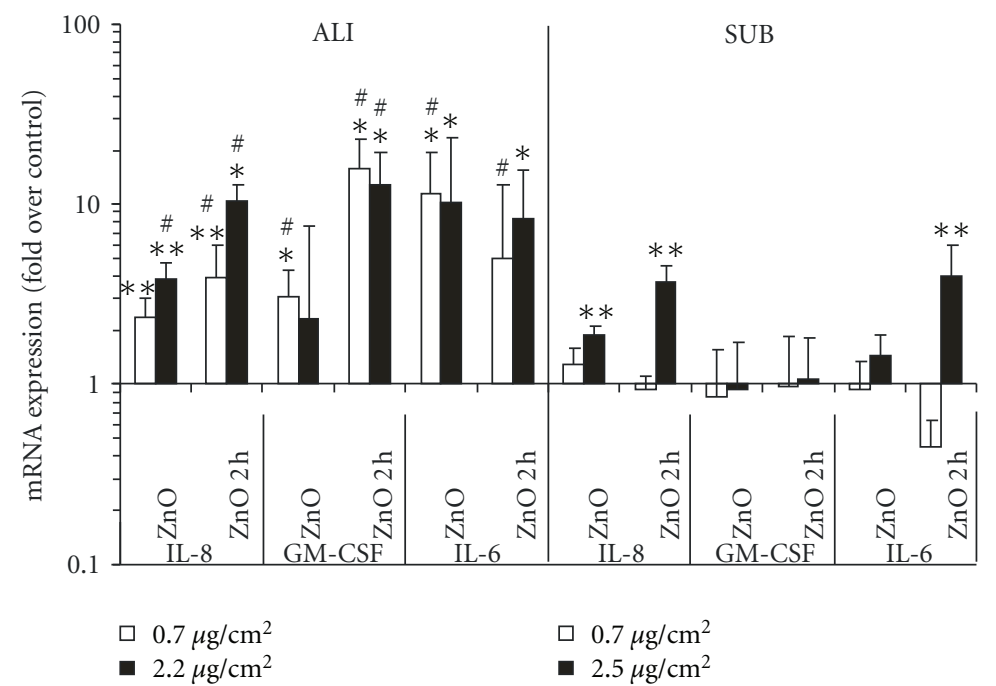

(a)

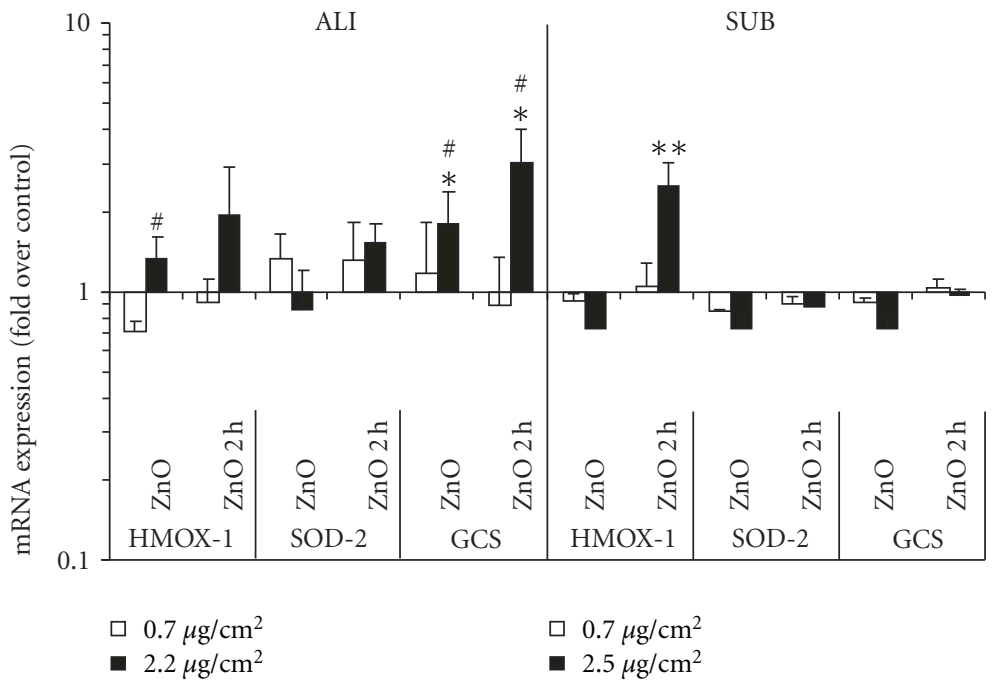

(b)

FIGURE 3: Comparison of the effect of ZnO on proinflammatory and oxidative stress markers in A549 cells following exposure at the ALI and under submerged (SUB) conditions. (a) mRNA expression of proinflammatory cytokines (IL-8, GM-CSF, and IL-6) was measured with RT-PCR either directly after ( $0 \mathrm{~h}$ after incubation) or two hours after the exposure ( $2 \mathrm{~h}$ ). (b) Same as (a), but for oxidative stress markers (HMOX1, SOD-2, and GCS). The postincubation of the cells after ALI exposure was also performed under submerged conditions. The mRNA values were normalized to glyceraldehyde-3-phosphate dehydrogenase (GAPDH) levels and expressed as the fold increase over control (the control level was set to unity) which was filtered air and pure medium for ALI and SUB, respectively. The data show the geometric means and geometric standard error of the mean based on 4 to 7 independent experiments. Due to differences in the deposition kinetics described in the experimental section, the final dose was delivered to the cells after $3 \mathrm{~h}$ (ALI, open bars $0.7 \mu \mathrm{g} / \mathrm{cm}^{2}$ and solid bars $2.2 \mu \mathrm{g} / \mathrm{cm}^{2}$ ) or $1 \mathrm{~h}$ (submerged, open bars $0.7 \mu \mathrm{g} / \mathrm{cm}^{2}$ and solid bars $2.5 \mu \mathrm{g} / \mathrm{cm}^{2}$ ). The symbol $(*)$ indicates significant differences from control levels at $P<0.05$, and $(* *)$ at $P<0.01$. The symbol (\#) indicates mRNA values which are statistically different from the corresponding submerged mRNA levels (differences are 2.8 to 12 -fold $(P>0.05)$ ).

that the currently recommended Occupational Safety and Health Administration (OSHA) standard for $\mathrm{ZnO}$ fume (and many other occupational dusts) is $5 \mathrm{mg}$ of $\mathrm{ZnO}$ fume per cubic meter of air $\left(\mathrm{mg} / \mathrm{m}^{3}\right)$ averaged over an eight-hour-perday work shift. Assuming an accumulated breathing volume of $3 \mathrm{~m}^{3}$ in $8 \mathrm{~h}$, a lung surface area of $140 \mathrm{~m}^{2}$, an alveolar deposition efficiency of $10-50 \%$ depending on particle size, and negligible clearance from the alveolar regime within $24 \mathrm{~h}$
[52], the OSHA standard corresponds to a daily alveolar surface dose of $1.1-5.4 \mathrm{ng} / \mathrm{cm}^{2}$, which is about 3 orders of magnitudes smaller than what was deposited during the $\mathrm{ZnO}$ ALI exposures performed here $\left(0.7-2.2 \mu \mathrm{g} / \mathrm{cm}^{2}\right)$. Furthermore, it can be seen from Table 1 that the LOEL during submerged exposures is typically between 1 and $65 \mu \mathrm{g} / \mathrm{cm}^{2}$, which is in the range of the expected lifetime dose $\left(4-18 \mu \mathrm{g} / \mathrm{cm}^{2}\right)$ under worst case conditions represented by 
a worker exposed to the OSHA $(\mathrm{ZnO})$ dust limit $\left(5 \mathrm{mg} / \mathrm{m}^{3}\right)$ for 5 days per week, 50 weeks per year for 45 years (where we assumed that only about $30 \%$ of the lung-deposited particles remain in the alveoli due to alveolar clearance mechanisms). As the in vitro dose is deposited onto the cells within a few hours instead of 45 years, this does not represent a realistic in vivo exposure scenario. In spite of these unrealistically high dose levels, in vitro cell tests are useful for pharmacological and toxicological prescreening of substances and studies of cellular response mechanisms, but lower cellular doses may be desirable. Table 1 suggests that an incremental progress may be possible with ALI cell systems. In combination with other measures such as the use of multicell cocultures instead of single-cell cultures, this may lead to significantly more realistic in vitro dose rates in the future.

\section{Conclusion}

In this study the in vitro response of pulmonary epithelial cells to different types of (nano-)particles was compared for air-liquid interface (ALI) and submerged exposure conditions. The scarce data pool on this issue was expanded by presenting the first ALI data on airborne agglomerates of $\mathrm{ZnO}$ nanoparticles using alveolar epithelial-like type II cells (A549). For ZnO, the lowest observed effect levels (LOELs) of the proinflammatory markers (mRNA gene expression of IL-8, IL-6, and GM-CSF) were lower under ALI than under submerged conditions, while no significant response was observed for most of the oxidative stress markers (HMOX1, SOD-2, and GCS). These findings are consistent with the few previous comparative studies on this issue indicating that toxicity testing with the conventional submerged systems may yield more false negatives than the more recently developed ALI systems.

The dose levels used here and in similar studies reported in the literature are in the range of an entire lifetime dose of occupational dust received by a heavily exposed worker. The ability to induce cellular responses at somewhat lower and hence more realistic dose levels under ALI conditions may provide biologically more meaningful data than those obtainable with the conventional submerged exposures. Further advantages of ALI cell systems include the biologically more realistic exposure scenario (cells in the lungs are exposed under ALI-like not submerged conditions), the absence of inadvertent modifications of the particle properties in the cell culture medium (e.g., agglomeration, partial dissolution), and the possibility of direct dose measurement (e.g., quartz crystal microbalance). Depending on the application, these aspects may outweigh the larger experimental complexity of ALI exposures. However, quantitative comparisons of the cellular response under ALI and submerged culture conditions are still very limited. Thus, further studies are needed to address these issues.

\section{References}

[1] H. Schulz, V. Harder, A. Ibald-Mulli et al., "Cardiovascular effects of fine and ultrafine particles," Journal of Aerosol Medicine, vol. 18, no. 1, pp. 1-22, 2005.
[2] R. Rückerl, A. Ibald-Mulli, W. Koenig et al., "Air pollution and markers of inflammation and coagulation in patients with coronary heart disease," American Journal of Respiratory and Critical Care Medicine, vol. 173, no. 4, pp. 432-441, 2006.

[3] A. Peters, H. E. Wichmann, T. Tuch, J. Heinrich, and J. Heyder, "Respiratory effects are associated with the number of ultrafine particles," American Journal of Respiratory and Critical Care Medicine, vol. 155, no. 4, pp. 1376-1383, 1997.

[4] T. Stoeger, C. Reinhard, S. Takenaka et al., "Instillation of six different ultrafine carbon particles indicates a surface area threshold dose for acute lung inflammation in mice," Environmental Health Perspectives, vol. 114, no. 3, pp. 328-333, 2006.

[5] R. Duffin, L. Tran, D. Brown, V. Stone, and K. Donaldson, "Proinflammogenic effects of low-toxicity and metal nanoparticles in vivo and in vitro: highlighting the role of particle surface area and surface reactivity," Inhalation Toxicology, vol. 19, no. 10, pp. 849-856, 2007.

[6] T. Stoeger, S. Takenaka, B. Frankenberger et al., "Deducing in vivo toxicity of combustion-derived nanoparticles from a cell-Free oxidative potency assay and metabolic activation of organic compounds," Environmental Health Perspectives, vol. 117, no. 1, pp. 54-60, 2009.

[7] I. Y. R. Adamson, H. Prieditis, C. Hedgecock, and R. Vincent, "Zinc is the toxic factor in the lung response to an atmospheric particulate sample," Toxicology and Applied Pharmacology, vol. 166, no. 2, pp. 111-119, 2000.

[8] T. B. Councell, K. U. Duckenfield, E. R. Landa, and E. Callender, "Tire-wear particles as a source of zinc to the environment," Environmental Science and Technology, vol. 38, no. 15, pp. 4206-4214, 2004.

[9] M. L. Sammut, J. Rose, A. Masion et al., "Determination of zinc speciation in basic oxygen furnace flying dust by chemical extractions and X-ray spectroscopy," Chemosphere, vol. 70, no. 11, pp. 1945-1951, 2008.

[10] J. M. Fine, T. Gordon, L. C. Chen et al., "Characterization of clinical tolerance to inhaled zinc oxide in naive subjects and sheet metal workers," Journal of Occupational and Environmental Medicine, vol. 42, no. 11, pp. 1085-1091, 2000.

[11] W. G. Kuschner, A. D’Alessandro, H. Wong, and P. D. Blanc, "Early pulmonary cytokine responses to zinc oxide fume inhalation," Environmental Research, vol. 75, no. 1, pp. 7-11, 1997.

[12] M. Lindahl, P. Leanderson, and C. Tagesson, "Novel aspect on metal fume fever: Zinc stimulates oxygen radical formation in human neutrophils," Human and Experimental Toxicology, vol. 17, no. 2, pp. 105-110, 1998.

[13] R. J. Vandebriel and W. H. De Jong, "A review of mammalian toxicity of $\mathrm{ZnO}$ nanoparticles," vol. Nanotechnology, Science and Application, no. 5, pp. 61-71, 2012.

[14] G. J. Nohynek, J. Lademann, C. Ribaud, and M. S. Roberts, "Grey goo on the skin? Nanotechnology, cosmetic and sunscreen safety," Critical Reviews in Toxicology, vol. 37, no. 3, pp. 251-277, 2007.

[15] A. Nel, T. Xia, L. Mädler, and N. Li, “Toxic potential of materials at the nanolevel," Science, vol. 311, no. 5761, pp. 622-627, 2006.

[16] G. Oberdörster, E. Oberdörster, and J. Oberdörster, "Nanotoxicology: an emerging discipline evolving from studies of ultrafine particles," Environmental Health Perspectives, vol. 113, no. 7, pp. 823-839, 2005.

[17] T. Stoeger, O. Schmid, S. Takenaka, and H. Schulz, "Inflammatory response to $\mathrm{TiO}_{2}$ and carbonaceous particles scales best 
with BET surface area," Environmental Health Perspectives, vol. 115, no. 6, pp. A290-A291, 2007.

[18] T. Stoeger and O. Schmid, Dose-Response Relationships, Informa Healthcare, London, UK, 2009.

[19] K. M. Waters, L. M. Masiello, R. C. Zangar et al., "Macrophage responses to silica nanoparticles are highly conserved across particle sizes," Toxicological Sciences, vol. 107, no. 2, pp. 553-569, 2009.

[20] D. Shaw, Introduction to Colloid and Surface Chemistry, Butterworth Heinemann, Oxford, UK, 4th edition, 1992.

[21] E. Bitterle, E. Karg, A. Schroeppel et al., "Dose-controlled exposure of A549 epithelial cells at the air-liquid interface to airborne ultrafine carbonaceous particles," Chemosphere, vol. 65, no. 10, pp. 1784-1790, 2006.

[22] S. Diabaté, S. Mülhopt, H. R. Paur, and H. F. Krug, "The response of a co-culture lung model to fine and ultrafine particles of incinerator fly ash at the air-liquid interface," ATLA Alternatives to Laboratory Animals, vol. 36, no. 3, pp. 285-298, 2008.

[23] M. Savi, M. Kalberer, D. Lang et al., "A novel exposure system for the efficient and controlled deposition of aerosol particles onto cell cultures," Environmental Science and Technology, vol. 42, no. 15, pp. 5667-5674, 2008.

[24] A. L. Holder, D. Lucas, R. Goth-goldstein, and C. P. Koshland, "Cellular response to diesel exhaust particles strongly depends on the exposure method," Toxicological Sciences, vol. 103, no. 1, pp. 108-115, 2008.

[25] M. Aufderheide and U. Mohr, "A modified CULTEX system for the direct exposure of bacteria to inhalable substances," Experimental and Toxicologic Pathology, vol. 55, no. 6, pp. 451-454, 2004.

[26] J. Volckens, L. Dailey, G. Walters, and R. B. Devlin, "Direct particle-to-cell deposition of coarse ambient particulate matter increases the production of inflammatory mediators from cultured human airway epithelial cells," Environmental Science and Technology, vol. 43, no. 12, pp. 4595-4599, 2009.

[27] B. M. Rothen-Rutishauser, S. C. Kiama, and P. Gehr, "A threedimensional cellular model of the human respiratory tract to study the interaction with particles," American Journal of Respiratory Cell and Molecular Biology, vol. 32, no. 4, pp. 281-289, 2005.

[28] A. G. Lenz, E. Karg, B. Lentner et al., "A dose-controlled system for air-liquid interface cell exposure and application to zinc oxide nanoparticles," Particle and Fibre Toxicology, vol. 6, article $32,2009$.

[29] K. Donaldson and C. L. Tran, "Inflammation caused by particles and fibers," Inhalation Toxicology, vol. 14, no. 1, pp. 5-27, 2002.

[30] T. Xia, M. Kovochich, M. Liong et al., "Comparison of the mechanism of toxicity of zinc oxide and cerium oxide nanoparticles based on dissolution and oxidative stress properties," ACS Nano, vol. 2, no. 10, pp. 2121-2134, 2008.

[31] N. Li, T. Xia, and A. E. Nel, "The role of oxidative stress in ambient particulate matter-induced lung diseases and its implications in the toxicity of engineered nanoparticles," Free Radical Biology and Medicine, vol. 44, no. 9, pp. 1689-1699, 2008.

[32] K. A. Foster, C. G. Oster, M. M. Mayer, M. L. Avery, and K. L. Audus, "Characterization of the A549 cell line as a type II pulmonary epithelial cell model for drug metabolism," Experimental Cell Research, vol. 243, no. 2, pp. 359-366, 1998.
[33] A. Tippe, U. Heinzmann, and C. Roth, "Deposition of fine and ultrafine aerosol particles during exposure at the air/cell interface," Journal of Aerosol Science, vol. 33, no. 2, pp. 207-218, 2002.

[34] J. M. Desantes, X. Margot, A. Gil, and E. Fuentes, "Computational study on the deposition of ultrafine particles from Diesel exhaust aerosol," Journal of Aerosol Science, vol. 37, no. 12, pp. 1750-1769, 2006.

[35] P. A. Baron and K. Willeke, Aerosol Measurement, WileyInterscience, New York, NY, USA, 2001.

[36] M. Kaszuba, M. T. Connah, F. K. McNeil-Watson, and U. Nobbmann, "Resolving concentrated particle size mixtures using dynamic light scattering," Particle and Particle Systems Characterization, vol. 24, no. 3, pp. 159-162, 2007.

[37] O. Schmid, E. Karg, D. E. Hagen, P. D. Whitefield, and G. A. Ferron, "On the effective density of non-spherical particles as derived from combined measurements of aerodynamic and mobility equivalent size," Journal of Aerosol Science, vol. 38, no. 4, pp. 431-443, 2007.

[38] J. Gebhart, Optical Direct-Reading Techniques: Light Intensity Systems, Wiley Interscience, New York, NY, USA, 2001.

[39] J. G. Teeguarden, P. M. Hinderliter, G. Orr, B. D. Thrall, and J. G. Pounds, "Particokinetics in vitro: Dosimetry considerations for in vitro nanoparticle toxicity assessments," Toxicological Sciences, vol. 95, no. 2, pp. 300-312, 2007.

[40] B. T. Smith, "Cell line A549: a model system for the study of alveolar type II cell function," American Review of Respiratory Disease, vol. 115, no. 2, pp. 285-293, 1977.

[41] A. W. Stadnyk, "Cytokine production by epithelial cells," FASEB Journal, vol. 8, no. 13, pp. 1041-1047, 1994.

[42] H. Fehrenbach, "Alveolar epithelial type II cell: defender of the alveolus revisited," Respiratory Research, vol. 2, no. 1, pp. 33-46, 2001.

[43] E. L. Herzog, A. R. Brody, T. V. Colby, R. Mason, and M. C. Williams, "Knowns and unknowns of the alveolus," Proceedings of the American Thoracic Society, vol. 5, no. 7, pp. 778-782, 2008.

[44] A. D. P. Carero, P. H. M. Hoet, L. Verschaeve, G. Schoeters, and B. Nemery, "Genotoxic effects of carbon black particles, diesel exhaust particles, and urban air particulates and their extracts on a human alveolar epithelial cell line (A549) and a human monocytic cell line (THP-1)," Environmental and Molecular Mutagenesis, vol. 37, no. 2, pp. 155-163, 2001.

[45] E. Herzog, H. J. Byrne, A. Casey et al., "SWCNT suppress inflammatory mediator responses in human lung epithelium in vitro," Toxicology and Applied Pharmacology, vol. 234, no. 3, pp. 378-390, 2009.

[46] R. B. Reed, D. A. Ladner, C. P. Higgins, P. Westerhoff, and J. F. Ranville, "Solubility of nano-zinc oxide in environmentally and biologically important matrices," Environmental Toxicology and Chemistry, vol. 31, no. 1, pp. 93-99, 2012.

[47] H. R. Paur, F. R. Cassee, J. Teeguarden et al., "In-vitro cell exposure studies for the assessment of nanoparticle toxicity in the lung-a dialog between aerosol science and biology," Journal of Aerosol Science, vol. 42, no. 10, pp. 668-692, 2011.

[48] P. M. Hinderliter, K. R. Minard, G. Orr et al., "ISDD: a computational model of particle sedimentation, diffusion and target cell dosimetry for in vitro toxicity studies," Particle and Fibre Toxicology, vol. 7, no. 1, article 36, 2010.

[49] S. Kameyama, M. Kondo, K. Takeyama, and A. Nagai, "Air exposure causes oxidative stress in cultured bovine tracheal epithelial cells and produces a change in cellular glutathione 
systems," Experimental Lung Research, vol. 29, no. 8, pp. 567-583, 2003.

[50] F. Blank, B. M. Rothen-Rutishauser, S. Schurch, and P. Gehr, "An optimized in vitro model of the respiratory tract wall to study particle cell interactions," Journal of Aerosol Medicine, vol. 19, no. 3, pp. 392-405, 2006.

[51] A. J. Ross, L. A. Dailey, L. E. Brighton, and R. B. Devlin, "Transcriptional profiling of mucociliary differentiation in human airway epithelial cells," American Journal of Respiratory Cell and Molecular Biology, vol. 37, no. 2, pp. 169-185, 2007.

[52] W. G. Kreyling, J. J. Godleski, S. T. Kariya, R. M. Rose, and J. D. Brain, "In vitro dissolution of uniform cobalt oxide particles by human and canine alveolar macrophages," American Journal of Respiratory Cell and Molecular Biology, vol. 2, no. 5, pp. 413-422, 1990. 

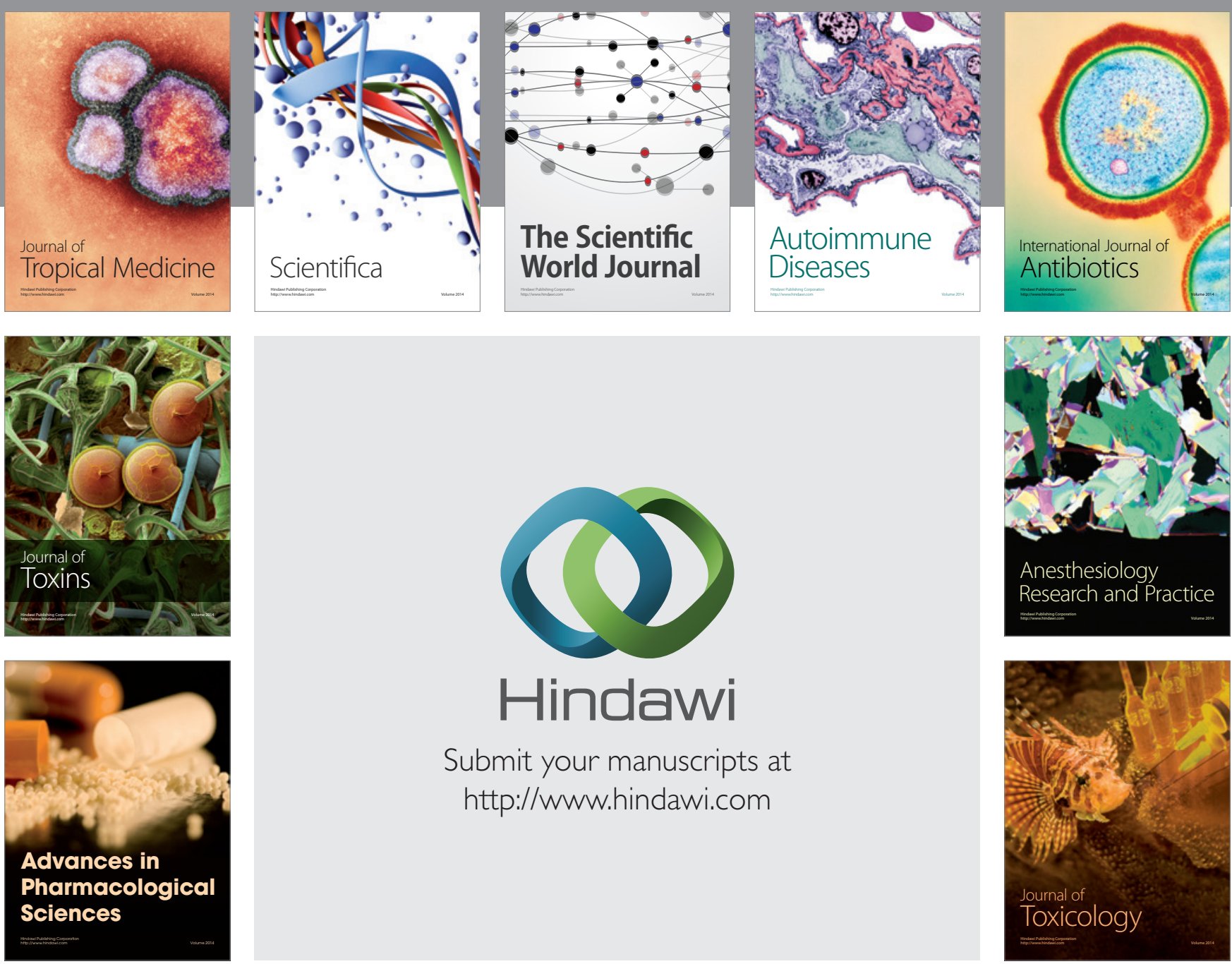

\section{Hindawi}

Submit your manuscripts at

http://www.hindawi.com
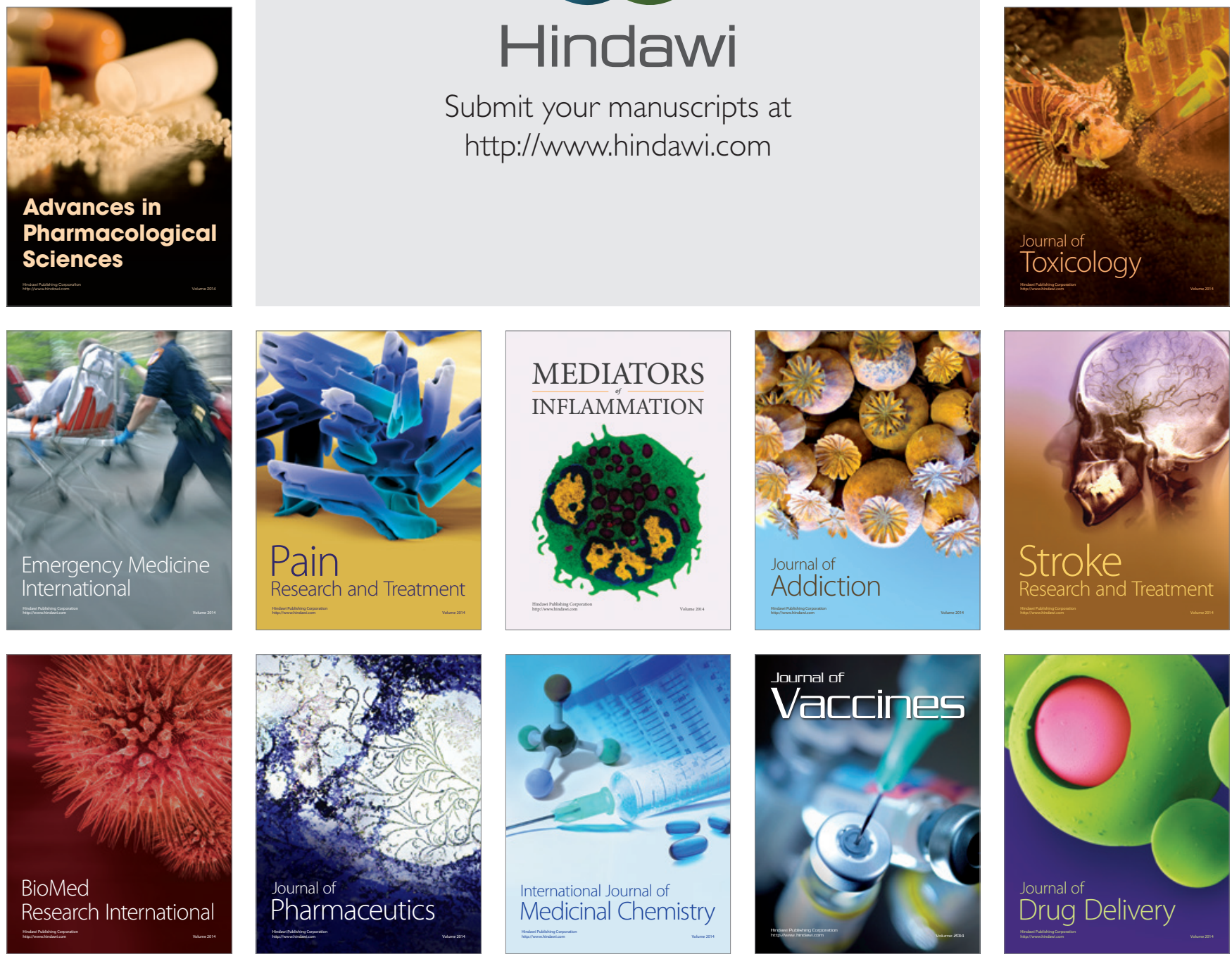